\title{
Surgical Treatment of Biliary Strictures after Liver Transplantation: A Single Center Experiences
}

\author{
Gokhan Ertugrul $^{1 *}$ and Tumay Yanaral $^{2}$ \\ ${ }^{1}$ Organ Transplantation Center, Medipol University Faculty of Medicine, Istanbul, Turkey \\ ${ }^{2}$ Department of Anesthesiology, Medipol University Faculty of Medicine, Istanbul, Turkey
}

*Corresponding author: Gokhan Ertugrul, Organ Transplantation Center Medipol University, Faculty of Medicine, TEM Avrupa Otoyolu Göztepe Çıkışı No:1; 34214, Bagcılar, Istanbul, Turkey, Tel: +902124607777; Fax: +902124706060; Email: mdgertugrul@gmail.com

\begin{abstract}
Aim: Liver transplantation is the only treatment for end-stage liver disease. Biliary tract pathologies that develop after liver transplantation are the most common causes of morbidity. The aim of this retrospective study was to evaluate the outcomes of surgical treatment for biliary strictures.

Patients and Methods: In this study, only surgical treatment applied biliary strictures were evaluated. Between April 2014 and April 2018 at Medipol University Medical Faculty Hospital Organ Transplantation Department, Istanbul, Turkey, 129 patients with living donor liver transplantation were studied retrospectively.

Results: Seven patients $(5.4 \%)$ were done surgical treatment, because all percutaneous transhepatic biliary drainage (PTBD) has failed. In these patients, no exhibited postoperative morbidity, mortality and recurrence of biliary strictures in follow up 35 months.

Conclusions: Surgical treatment appears to be successful in when PTBD have failed biliary stricture patients, after liver transplantation.
\end{abstract}

Keywords: Liver transplantation; Biliary strictures; Surgical treatment

Received Date: September 12, 2019; Accepted Date: September 20, 2019; Published Date: September 27, 2019

\section{Introduction}

Living donor liver transplantation (LDLT) was first reported in 1988 and right hepatic lobe was reported in 1994. Since that time, LDLT using the right lobe has become a standard treatment for end-stage liver disease in adults [1-3].

Citation: Gokhan Ertugrul, Surgical Treatment of Biliary Strictures after Liver Transplantation: A Single Center Experiences. J Clin Cases Rep 3(3): 69-74. 
There are two main techniques for biliary reconstruction in LDLT using the right lobe: duct-to-duct anastomosis, and Rouxen-Y hepaticojejunostomy [4]. The most common complications after LDLT develop from the biliary system. These are bile leakage and strictures $[5,6]$.

There are two main treatments for biliary strictures: interventional treatment and surgical treatment. Surgical treatment is performed when all interventional treatments have failed [7].

The aim of this retrospective study was to evaluate the outcomes of surgical treatment for biliary strictures.

\section{Patients and Methods}

In this study, only surgical treatment for biliary strictures was evaluated. Between April 2014 and April 2018 at Medipol University Medical Faculty Hospital Organ Transplantation Department, Istanbul, Turkey, 129 patients with living donor liver transplantation were studied retrospectively. Seven patients (5.4\%) were done surgical treatment for biliary stricture. In these patients were evaluated demographic features, complication rates and mortality rates.

\section{Post-transplant follow-up}

The patient will be used as a standard immunosuppressive therapy for life-long calcineurin inhibitors (tacrolimus or cyclosporine). Mycophenolate Mofetil to be used in the first year, the first six months were used Prednisolone to be used.

Patients received control once a week for the first month after discharge, and once every 15 days for the second month and monthly for the following months.

If liver biochemical parameters, such as serum total and direct bilirubin, alkaline phosphatase and gamma-glutamyl transferase, were abnormal in controls. We used ultrasonography (USG) and magnetic resonance cholangiopancreatography (MRCP) for radiologic diagnosis in doubt biliary strictures. If minimal dilatation of the intrahepatic biliary duct had observed on USG, MRCP was performed.

Magnetic resonance cholangiopancreatography (MRCP) was performed when biliary complications were suspected. A biliary stricture was diagnosed when stenosis of the bile duct and dilatation of the intrahepatic duct proximal to the stricture were observed on MRCP (Figure 1).

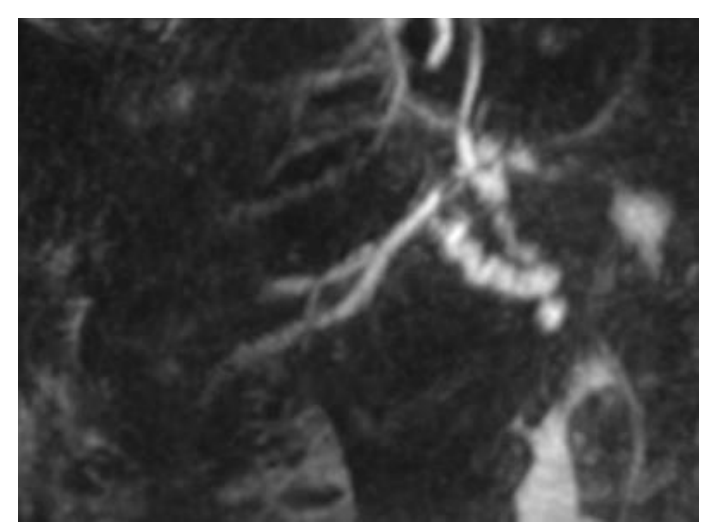

Figure 1: Magnetic resonance cholangio pancreatography (MRCP). 
Whether PTBD is chosen as the first treatment after diagnosis of a biliary stricture depends on the status of the biliary stricture and the patient's condition. Surgical treatment is performed when all PTBD treatments have failed (Figure 2).

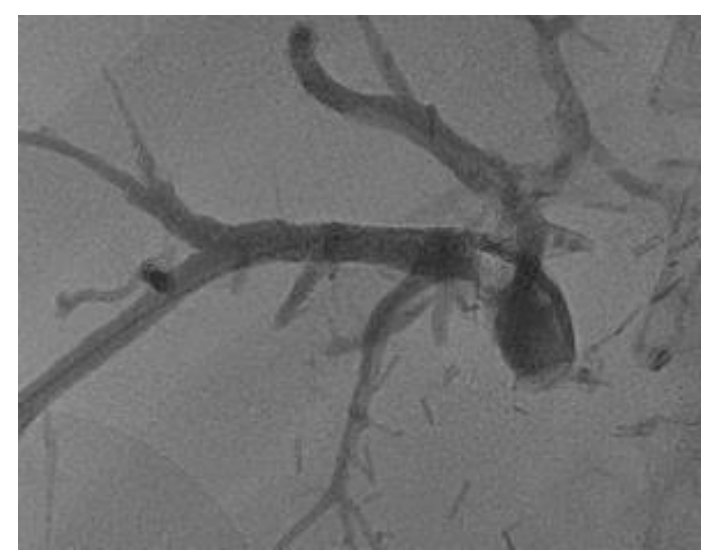

Figure 2: Percutaneous transhepatic biliary drainage (PTBD).

\section{Surgical treatment}

Unsuccessful interventional treatment was mostly attributed to critical narrowing not allowing traversing the stricture. These patients were referred for surgery. In our patients, we have disrupted the duct to duct anastomosis and we have performed Roux-en-Y hepaticojejunostomy.

\section{Statistical Analysis}

SPSS 22.0 (SPSS for Windows, 2007, Chicago) was used for statistical analysis. Continuous variables which have normal distribution were presented as mean \pm Standard deviation. Statistical analysis for the parametric variables was performed by the Student's T-test. The qualitative variables were given as percent and the correlation between categorical variables was investigated by the chi-square test and Fisher's exact test. Statistical significance level was defined as $\mathrm{P}<0.05$.

\section{Results}

Among 129 recipients, seven patients (5.4\%) were done surgical treatment for biliary stricture. Mean age of surgical treatment patients were $50.7 \pm 10.5$ years; $6(85.7 \%)$ of the 7 surgical treatment patients were male.

Mean Body Mass Index (BMI) of surgical treatment patients were $29.1 \pm 4.30 \mathrm{~kg} / \mathrm{m}^{2}$ (kilogram per square meter).

Mean model for end-stage liver disease (MELD) scores of surgical treatment patients were 19.4 \pm 11.2 .

Mean warm ischemia time of surgical treatment patients were $50.6 \pm 8.6$ minutes.

Mean Cold ischemia time of surgical treatment patients were $26.7 \pm 10.4$ minutes.

The mean follow-up time was 35 (22-42) months.

In these patients, no exhibited postoperative morbidity, mortality and recurrence of biliary strictures in follow up period (Table 1). 


\begin{tabular}{|l|c|c|c|}
\hline & $\begin{array}{c}\text { None Stricture Group } \\
(\mathbf{n = 1 2 2})\end{array}$ & $\begin{array}{c}\text { Surgical Treatment for Biliary } \\
\text { Stricture Group (n= 7) }\end{array}$ & P-value \\
\hline Age (years) & $51.8 \pm 12.1$ & $50.7 \pm 10.5$ & 0.812 \\
\hline Male/female (n/\%) & $76(62.3 \%) / 46(37.7 \%)$ & $6(85.7 \%) / 1(14.3 \%)$ & 0.421 \\
\hline $\begin{array}{l}\text { Body mass index kilogram per } \\
\text { square meter (kg/m })\end{array}$ & $28.3 \pm 5.01$ & $29.1 \pm 4.30$ & 0.694 \\
\hline Warm ischemia time (minute) & $39.2 \pm 11.9$ & $50.6 \pm 8.6$ & $\mathbf{0 . 0 1 5}$ \\
\hline Cold ischemia time (minute) & $29.6 \pm 12.7$ & $26.7 \pm 10.4$ & 0.550 \\
\hline $\begin{array}{l}\text { Model for end-stage liver disease } \\
\text { (MELD) score }\end{array}$ & $16.3 \pm 7.02$ & $19.4 \pm 11.2$ & 0.279 \\
\hline
\end{tabular}

Table 1: Comparison of demographic and clinical findings

\section{Discussion}

Living donor liver transplantation using the right lobe has become a standard treatment in adults [1]. There are two methods of biliary reconstruction in recipients using the right lobe; Roux-en-Y hepaticojejunostomy and duct-to-duct anastomosis [4]. In all patients included this study there was duct-to-duct biliary anastomosis before development biliary strictures.

Biliary complications are the most common and cause of morbidity and mortality in LDLT patients. These are bile leakage and strictures $[5,6]$. The incidence of biliary leakage and stricture after LDLT using the right lobe are reportedly $4.7 \%$ to $18.2 \%$ and $8.3 \%$ to $31.7 \%$, respectively [7,8]. Biliary strictures can occur months to years after liver transplant [9].

In this study, there was most commonly seen within the first six months.

In this study, only performed surgical treatment for biliary stricture seven patients (5.4\%) were evaluated.

The clinical presentation of patients with biliary strictures after liver transplant is generally the result of obstruction to bile outflow and cholangitis. The clinical findings can include jaundice, abdominal pain, fever, and pruritus [10]. Elevated alkaline phosphatase, gamma glutamyl transferase, total-direct bilirubin and transaminase levels [11].

In our study, the clinical findings were fever, pruritus and the liver profile to be elevated in a cholestatic pattern.

The radiologic diagnosis of biliary strictures ultrasonography (USG) and Magnetic resonance cholangiopancreatography (MRCP). USG has sensitivity in the detection of bile duct obstruction 40\% and 70\% [12]. MRCP has a sensitivity of 95\% [13].

In this study, we used ultrasonography (USG) and magnetic resonance cholangiopancreatography (MRCP) for radiologic diagnosis in doubt biliary strictures. If minimal dilatation of the intrahepatic biliary duct had observed on USG, MRCP was performed. 
http://www.tridhascholars.org | July-2020

Magnetic resonance cholangiopancreatography (MRCP) was performed when biliary complications were suspected. A biliary stricture was diagnosed when stenosis of the bile duct and dilatation of the intrahepatic duct proximal to the stricture were observed on MRCP.

The management of biliary strictures after liver transplantation can be divided into 4 therapeutic strategies: Endoscopic retrograde cholangiopancreatography $(E R C P)$, Percutaneous transhepatic biliary drainage (PTBD), surgical revision and retransplantation. Surgical treatment is performed when all interventional treatments have failed [14].

In our study, surgical treatment is performed when all PTBD have failed.

The rate of recurrence of post-transplant biliary strictures ranges from $10 \%$ to $20 \%$ [15].

The mean follow-up time was 35 (22-42) months. In these patients, no exhibited postoperative morbidity, mortality and recurrence of biliary strictures in follow up period.

Our study has several limitations. First, this study was retrospective. Second, the number of cases was small.

\section{Conclusion}

Despite the limitations described in discussion, surgical treatment appears to be successful in when PTBD have failed biliary stricture patients, after liver transplantation.

\section{References}

1. Hashikura Y, Makuuchi M, Kawasaki S, et al. (1994) Successful living-related partial liver transplantation to an adult patient. The Lancet 343(8907): 1233-1234.

2. Liu CL, Fan ST, Lo CM, et al. (2006) Operative outcomes of adult-to-adult right lobe live donor liver transplantation: A comparative study with cadaveric whole-graft liver transplantation in a single center. Annals of Surgery 243(3): 404-410.

3. Yamaoka Y, Washida M, Honda K, et al. (1994) Liver transplantation using a right lobe graft from a living related donor. Transplantation 57(7): 1127-1141.

4. Fan ST, Lo CM, Liu CL, et al. (2002) Biliary reconstruction and complications of right lobe live donor liver transplantation. Annals of Surgery 236(5): 676-683.

5. Jagannath S, Kalloo AN (2002) Biliary complications after liver transplantation. Current Treatment Options in Gastroenterology 5(2): 101-112.

6. Qian YB, Liu CL, Lo CM, et al. (2004) Risk factors for biliary complications after liver transplantation. Archives of Surgery 139(10): 1101-1105.

7. Wojcicki M, Milkiewicz P, Silva M (2008) Biliary tract complications after liver transplantation: A review. Digestive Surgery 25(4): 245-257.

8. Hwang S, Lee SG, Sung KB, et al. (2006) Long-term incidence, risk factors, and management of biliary complications after adult living donor liver transplantation. Liver Transplantation 12(5): 831-838.

9. Williams ED, Draganov PV (2009) Endoscopic management of biliary strictures after liver transplantation. World Journal of Gastroenterology 15(30): 3725-3733. 
http://www.tridhascholars.org | July-2020

10. Ayoub WS, Esquivel CO, Martin P (2010) Biliary complications following liver transplantation. Digestive Diseases and Sciences 55(6): 1540-1546.

11. Morelli J, Mulcahy HE, Willner IR, et al. (2003) Long-term outcomes for patients with post-liver transplant anastomotic biliary strictures treated by endoscopic stent placement. Gastrointestinal Endoscopy 58(3): 374-379.

12. Sharma S, Gurakar A, Camci C, et al. (2009) Avoiding pitfalls: What an endoscopist should know in liver transplantationpart II. Digestive Diseases and Sciences 54(7): 1386-1402.

13. Valls C, Alba E, Cruz M, et al. (2005) Biliary complications after liver transplantation: diagnosis with MR cholangiopancreatography. American Journal of Roentgenology 184(3): 812-820.

14. Akamatsu N, Sugawara Y, Hashimoto D (2011) Biliary reconstruction, its complications and management of biliary complications after adult liver transplantation: a systematic review of the incidence, risk factors and outcome. Transplant International 24(4): 379-392.

15. Alazmi WM, Fogel EL, Watkins JL, et al. (2006) Recurrence rate of anastomotic biliary strictures in patients who have had previous successful endoscopic therapy for anastomotic narrowing after orthotopic liver transplantation. Endoscopy 38(06): 571-574. 